\title{
Genetic inactivation of D-amino acid oxidase enhances extinction and reversal learning in mice
}

\author{
Viviane Labrie, ${ }^{1,2,6}$ Steven Duffy, ${ }^{1}$ Wei Wang, ${ }^{3}$ Steven W. Barger, ${ }^{3,4}$ \\ Glen B. Baker, ${ }^{5}$ and John C. Roder ${ }^{1,2}$ \\ ${ }^{1}$ Samuel Lunenfeld Research Institute, Mount Sinai Hospital, Toronto M5G 1X5, Canada; ${ }^{2}$ Institute of Medical Science, \\ University of Toronto, Toronto MSS 1A8, Canada; ${ }^{3}$ Department of Neurobiology and Developmental Sciences, \\ University of Arkansas for Medical Sciences, Little Rock, Arkansas 72205, USA; ${ }^{4}$ Department of Geriatrics, University of \\ Arkansas for Medical Sciences, Little Rock, Arkansas 72205, USA; ${ }^{5}$ Neurochemical Research Unit and Bebensee \\ Schizophrenia Research Unit, Department of Psychiatry, University of Alberta, Edmonton T6G 2G3, Canada
}

\begin{abstract}
Activation of the $\mathrm{N}$-methyl-D-aspartate receptor (NMDAR) glycine site has been shown to accelerate adaptive forms of learning that may benefit psychopathologies involving cognitive and perseverative disturbances. In this study, the effects of increasing the brain levels of the endogenous NMDAR glycine site agonist D-serine, through the genetic inactivation of its catabolic enzyme D-amino acid oxidase (DAO), were examined in behavioral tests of learning and memory. In the Morris water maze task (MWM), mice carrying the hypofunctional Daol ${ }^{G 181 R}$ mutation demonstrated normal acquisition of a single platform location but had substantially improved memory for a new target location in the subsequent reversal phase. Furthermore, Daol ${ }^{G 181 R}$ mutant animals exhibited an increased rate of extinction in the MWM that was similarly observed following pharmacological administration of D-serine $(600 \mathrm{mg} / \mathrm{kg})$ in wild-type C57BL/6) mice. In contextual and cued fear conditioning, no alterations were found in initial associative memory recall; however, extinction of the contextual fear memory was facilitated in mutant animals. Thus, an augmented level of D-serine resulting from reduced DAO activity promotes adaptive learning in response to changing conditions. The NMDAR glycine site and DAO may be promising therapeutic targets to improve cognitive flexibility and inhibitory learning in psychiatric disorders such as schizophrenia and anxiety syndromes.
\end{abstract}

\begin{abstract}
The $N$-methyl-D-aspartate receptor (NMDAR) has an important role in excitatory neurotransmission and contributes to numerous brain processes, including synaptic plasticity, learning, and memory formation (Nicoll 2003). Activation of NMDARs requires membrane depolarization in addition to concurrent binding of glutamate to NMDAR2 (NR2) and glycine to the NMDAR1 (NR1) subunit (Johnson and Ascher 1987; Clements and Westbrook 1991). D-serine has also been shown to be an endogenous coagonist for the NR1 glycine site, acting with high selectivity and a potency similar to or greater than that of glycine (Matsui et al. 1995). In the brain, the localization of D-serine closely resembles that of NMDARs (Schell et al. 1997), and D-serine has been reported to be the predominant physiologic co-agonist for the maintenance of NMDAR-mediated currents in the hippocampus, retina, and hypothalamus (Mothet et al. 2000; Yang et al. 2003). Moreover, in vivo studies have demonstrated that the NMDAR glycine site is not saturated at the synapses of several brain regions (Fuchs et al. 2005). Consequently, increasing D-serine levels may modulate neurotransmission and behavioral responses reliant on NMDAR activity.

The NMDAR glycine site has been implicated in the pathophysiology and treatment of a number of psychiatric conditions (Coyle and Tsai 2004; Millan 2005). Blockade of the NMDAR with noncompetitive antagonists like phencyclidine results in the production and exacerbation of schizophrenic-like symptoms in humans and animals (Javitt and Zukin 1991; Krystal et al. 1994). Genetic studies have associated genes that mediate D-serine syn-
\end{abstract}

\footnotetext{
${ }^{6}$ Corresponding author.
}

E-mail labrie@lunenfeld.ca; fax (416) 586-8588.

Article is online at http://www.learnmem.org/cgi/doi/10.1101/lm.1112209. thesis and degradation with a vulnerability to schizophrenia, and levels of D-serine are decreased in the CSF and serum of schizophrenic patients (Chumakov et al. 2002; Hashimoto et al. 2003, 2005; Schumacher et al. 2004; Morita et al. 2007). These observations prompted clinical trials with direct and indirect activators of the NMDAR glycine site, including D-serine, and improvements were revealed when these compounds were added to conventional antipsychotic regimes, particularly with the negative and cognitive symptoms of schizophrenia (Tsai et al. 1998; Coyle and Tsai 2004; Heresco-Levy et al. 2005). Furthermore, altered NMDAR activation has also been shown to affect extinction, a learning process that may be of benefit in anxiety illnesses, such as posttraumatic stress syndrome and obsessive-compulsive disorder (Davis et al. 2006). In rodents, extinction was shown to be impaired following inhibition of NMDARs in contextual fear conditioning, inhibitory avoidance, and eyeblink conditioning tasks (Kehoe et al. 1996; Lee and Kim 1998; Szapiro et al. 2003). In contrast, the partial NMDAR agonist D-cycloserine facilitated the extinction of fear memories in rodents and individuals with phobias and other anxiety disorders (Ressler et al. 2004; Ledgerwood et al. 2005; Norberg et al. 2008). Thus, the NMDAR glycine site and its related modulatory proteins may be important targets for the amelioration of psychopathologies involving cognitive dysfunction and maladaptive behaviors.

Endogenous levels of D-serine in the brain are regulated by its catabolic enzyme, D-amino acid oxidase (DAO); by the D-serine synthesis enzyme, serine racemase (Srr); and by neuronal and glial transporters (Foltyn et al. 2005; Martineau et al. 2006). Agents targeting such proteins may prove to be an effective method of increasing cerebral D-serine and occupancy of the NMDAR glycine site, which could overcome the difficulties D-serine and similar 
compounds have with penetrating the blood-brain barrier (Coyle and Tsai 2004; Bauer et al. 2005). Inhibiting DAO function in the brain is of particular interest as it would circumvent any nephrotoxicity associated with high levels of systemic D-serine (Maekawa et al. 2005a). DAO is a peroxisomal flavoprotein that at physiological $\mathrm{pH}$ is highly selective for D-serine, and in the brain, DAO is located predominantly in astrocytes (Mothet et al. 2000). An inverse correlation between the brain distribution of DAO and Dserine evinces the efficacy of this enzyme, with the most abundant DAO expression located in the D-serine-sparse hindbrain and cerebellum (Schell et al. 1995; Moreno et al. 1999). To study the effects of limiting DAO function, we tested a line of mice carrying a single point mutation (G181R) that results in a complete lack of DAO activity and consequently augmented D-serine in serum and brain (Sasaki et al. 1992; Hashimoto et al. 1993). These mice have previously been shown to exhibit an in vitro increase in NMDARmediated excitatory postsynaptic currents in dorsal horn neurons of the spinal cord and an in vivo elevation of cGMP that is indicative of augmented NMDAR activity (Wake et al. 2001; Almond et al. 2006). This demonstrates that reduced DAO function is capable of augmenting NMDAR activation, and it may follow that cognitive and extinction processes influenced by NMDARs are enhanced in Dao $1^{G 181 R}$ mutant mice. To investigate this possibility, we assessed the effects of the Dao1 ${ }^{\text {G181R }}$ mutation on learning, memory, and extinction in Morris water maze (MWM) and in contextual and cued fear conditioning paradigms.

\section{Results}

\section{D-serine measurements in the brains of Daol ${ }^{G 181 R}$ mice}

To determine the effect of the Dao1 ${ }^{G 181 R}$ mutation on D-serine levels in C57BL/6J mice, HPLC analysis was employed. D-serine concentrations were found to be significantly elevated in Dao1 ${ }^{G 181 R}$ mutant animals (main effect of genotype; $F_{(1,83)}=$ 43.4, $P<0.001$ ) compared with wild-type animals (Fig. 1). Higher levels were found in whole brain, whole cortex, hippocampus, and especially cerebellum $(P<0.05)$. In contrast, D-serine levels did not differ in the prefrontal cortex and amygdala $(P>0.05)$. No changes were detected when hippocampus was assayed for the concentration of other amino acids, including aspartate, glutamate, L-serine, glutamine, glycine, arginine, alanine, and GABA $(P>0.05)$ (data not shown). A chemiluminescent assay measuring D-serine catabolism following exposure to the Rhodotorula gracilis DAO enzyme was also used to quantify D-serine in the hippocampus (wild type: $3.7 \pm 0.1 \mathrm{nmol} / \mathrm{mg}$ protein; mutant: $4.8 \pm 0.2 \mathrm{nmol} / \mathrm{mg}$ protein) and whole cortex (wild type: $2.5 \pm 0.2 \mathrm{nmol} / \mathrm{mg}$ protein; mutant: $3.8 \pm 0.2 \mathrm{nmol} / \mathrm{mg}$ protein) of Dao1 ${ }^{G 181 R}$ mice. D-serine concentrations were again found to be elevated in mutant animals (main effect of genotype: $F_{(1,27)}=65.7, P<0.001$ ) in both of these brain regions $(P<0.01)$.

\section{The effects of a loss of DAO function in spatial reversal learning and memory}

Administration of exogenous D-serine has previously been shown to improve spatial reversal learning in the MWM (Duffy et al. 2008). Consequently, we examined the effect of genetic inactivation of DAO and enhanced levels of endogenous D-serine in this hippocampus-dependent behavioral task. Initially, a control experiment was done where animals were placed into the MWM for a 300-sec acclimatization period without the platform. This verified that the Dao1 $1^{G 181 R}$ mice did not have an inherent bias for a quadrant location or alterations in swimming behavior (Table 1 , left column). Additionally, similar performance was observed in a control experiment involving a visible platform session, indicating comparable sensorimotor abilities and motivation (Table 1,

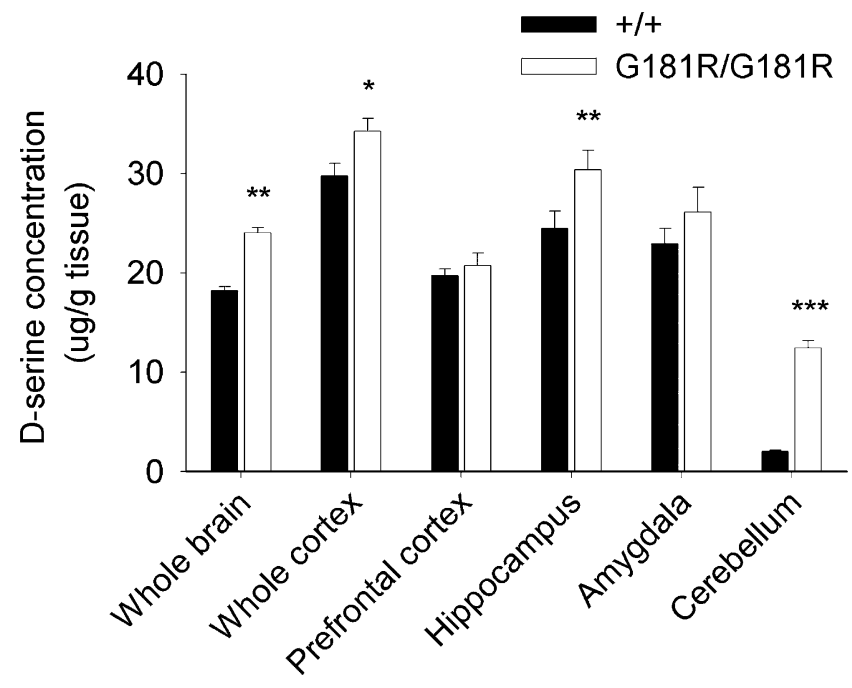

Figure 1. $\mathrm{D}$-serine concentrations in the brains of wild-type $(+/+)$ and Dao1 ${ }^{\text {G181R }}$ mutant (G181R/G181R) mice. HPLC was used to measure Dserine levels in whole brain and isolated brain regions including whole cortex, prefrontal cortex, hippocampus, amygdala, and cerebellum. $n=$ 7-9 per group; ${ }^{\star} P<0.05,{ }^{\star \star} P<0.01,{ }^{* *} P<0.001$ compared with wildtype mice, within the same brain structure.

left column). Afterward, spatial acquisition and reversal learning were tested in the MWM on a separate cohort of mice. The Dao1 ${ }^{\text {G181R }}$ mutation did not affect performance in a visible platform session or during the 7-d acquisition training phase when the platform was hidden, as demonstrated by a similar path length and latency to reach the platform (Fig. 2A). Also, swim speed, floating time, and thigmotaxis duration were not altered during the acquisition trials or in the subsequent reversal training phase (main effect of genotype in acquisition trials: swim speed: $F_{(1,24)}=$ $1.2, P=0.3$; floating time: $F_{(1,24)}=0.5, P=0.5$; thigmotaxis time: $F_{(1,24)}=4.1, P=0.1$; in reversal trials: swim speed: $F_{(1,24)}=0.2, P=$ 0.6 ; floating time: $F_{(1,24)}=0.1, P=0.8$; thigmotaxis time: $F_{(1,24)}=$ $1.7, P=0.2)$. Spatial memory in the acquisition probe, as measured by the amount of time spent and number of crosses in an area $2 \times$ the platform diameter centered over its former location did not differ between wild-type and mutant animals ( $P>0.05$; Fig. $2 \mathrm{~B}$ ). Additionally, both genotypes spent more time (main effect of platform location: $\left.F_{(1,24)}=44.1, P<0.001\right)$ and made more crosses over the target platform area (main effect of platform location: $\left.F_{(1,24)}=42.7, P<0.001\right)$ than the averaged analogous nontarget areas $(P<0.05$; wild-type nontarget: $\%$ time: $3.0 \pm 0.4$, crosses: $1.9 \pm 0.3$; mutant nontarget: \% time: $2.7 \pm 0.4$, crosses: $1.5 \pm 0.2$ ). A comparable performance between wild-type and mutant animals was also observed during reversal training, where the hidden platform was switched to a new location (Fig. 2A). However, memory for the new platform location was substantially improved in Dao1 ${ }^{G 181 R}$ mutant mice compared with wild-type animals in the reversal probe. Mutant mice spent more time (main effect of genotype: $F_{(1,25)}=5.3, P<0.05$; genotype $\times$ platform location interaction: $\left.F_{(2,50)}=7.9, P<0.01\right)$ and had a greater number of crosses (genotype $\times$ platform location interaction: $F_{(2,50)}=4.4, P<$ $0.05)$ over the reversal platform area than did wild-type animals $(P<$ 0.05; Fig. 2C). Wild-type and mutant mice both demonstrated a preference for the reversal target area (main effect of platform location: \% time: $F_{(2,50)}=32.3, P<0.001$; crosses: $F_{(2,50)}=31.0, P<$ $0.001)$ compared with the acquisition target and the averaged unbiased nontarget locations $(P<0.05)$, indicating that memory for the reversal target location was present in both genotypes but was particularly increased in mutant animals. 
Extinction in Dao1 ${ }^{G 181 R}$ mice

Table 1. Control experiments examining performance in acclimatization and visible platform sessions

\begin{tabular}{|c|c|c|c|c|c|}
\hline \multirow[b]{2}{*}{ Session } & \multirow[b]{2}{*}{ Behavioral variable } & \multicolumn{2}{|c|}{ Dao1 mice ${ }^{a}$} & \multicolumn{2}{|c|}{$\mathrm{C} 57 \mathrm{BL} / 6 \mathrm{~J}^{\mathrm{b}}$} \\
\hline & & $+/+$ & G181R/G181R & Saline & D-serine \\
\hline \multirow[t]{8}{*}{ Acclimatization } & $\%$ time in area $\mathrm{NE}^{\mathrm{C}}$ & $0.9 \pm 0.3$ & $0.7 \pm 0.2$ & $1.7 \pm 0.4$ & $1.4 \pm 0.5$ \\
\hline & $\%$ time in area SE (AT/ ExT) $)^{c, d}$ & $1.0 \pm 0.3$ & $1.1 \pm 0.4$ & $1.1 \pm 0.3$ & $1.4 \pm 0.4$ \\
\hline & $\%$ time in area $\mathrm{SW}^{\mathrm{c}}$ & $1.5 \pm 0.6$ & $1.7 \pm 0.3$ & $2.3 \pm 0.4$ & $1.8 \pm 0.4$ \\
\hline & $\%$ time in area NW $(\mathrm{RT})^{\mathrm{c}, \mathrm{d}}$ & $1.0 \pm 0.4$ & $1.9 \pm 0.4$ & $1.7 \pm 0.5$ & $1.8 \pm 0.6$ \\
\hline & Path length $(m)$ & $47.3 \pm 3.6$ & $47.1 \pm 2.9$ & $54.1 \pm 2.2$ & $53.1 \pm 2.7$ \\
\hline & Swim speed $(\mathrm{cm} / \mathrm{s})$ & $16.0 \pm 1.2$ & $15.8 \pm 1.0$ & $18.1 \pm 0.8$ & $17.7 \pm 0.9$ \\
\hline & Floating (\% time) & $6.6 \pm 5.7$ & $7.4 \pm 2.7$ & $2.3 \pm 0.6$ & $2.9 \pm 0.6$ \\
\hline & Thigmotaxis (\% time) & $77.3 \pm 6.6$ & $71.0 \pm 3.1$ & $63.3 \pm 5.0$ & $66.9 \pm 6.7$ \\
\hline \multirow[t]{5}{*}{ Visible platform } & Path length to target (m) & $7.8 \pm 0.7$ & $8.3 \pm 1.0$ & $6.5 \pm 1.1$ & $5.8 \pm 0.8$ \\
\hline & Latency to target $(\mathrm{sec})$ & $43.8 \pm 5.5$ & $40.6 \pm 4.1$ & $33.3 \pm 5.2$ & $31.9 \pm 4.5$ \\
\hline & Swim speed $(\mathrm{cm} / \mathrm{sec})$ & $17.6 \pm 1.0$ & $19.7 \pm 0.9$ & $19.1 \pm 0.6$ & $18.2 \pm 0.9$ \\
\hline & Floating (\% time) & $9.2 \pm 1.8$ & $8.4 \pm 2.7$ & $8.3 \pm 1.4$ & $7.1 \pm 1.1$ \\
\hline & Thigmotaxis (\% time) & $43.1 \pm 2.6$ & $40.6 \pm 4.0$ & $31.2 \pm 3.6$ & $34.2 \pm 2.9$ \\
\hline
\end{tabular}

Data are expressed as mean \pm SEM, $n=7-10$ per group. In the control experiments, no differences were found between genotype or drug treatment groups ( $P>0.05$ for all behavioral variables). In the acclimatization experiment, animals did not preferentially spend more time in any platform area (main effect of platform location: for $D a 01^{G 181 R}$ mice: $F_{(3,45)}=2.7, P=0.1$, for C57BL/6/ mice: $\left.F_{(3,36)}=1.8, P=0.2\right)$.

${ }^{a}$ Control experiments conducted for reversal and extinction studies with $D a 01^{\mathrm{Gl}}{ }^{(1 R}$ mice (Figs. 2, 3).

${ }^{b}$ Control experiments conducted for extinction study with D-serine treatments (Fig. 4).

${ }^{c}$ Chance level for each platform location is $2.6 \%$ (the ratio of the target area to the total pool area).

${ }^{\mathrm{d}} \mathrm{AT} / \mathrm{ExT}$ is the target platform in acquisition and extinction experiments, RT is the target platform in the reversal experiment.

\section{Modulation of extinction learning by a lack of DAO activity}

Considering that the Dao1 ${ }^{G 181 R}$ mutant mice expressed a specific improvement in reversal memory and the recent literature describing an enhancing effect of exogenous D-cycloserine on the extinction of learned responses (Davis et al. 2006), the Dao1 ${ }^{\text {G181R }}$ mice were examined in an extinction task in the MWM using repeated probe trials. The extinction procedure employed an experimentally naïve cohort of mice and was a separate experiment from the reversal learning study. In the visible and acquisition phases, wild-type and mutant mice demonstrated a similar performance, as measured by the path length and latency to find the visible or hidden platform (Fig. 3A). In the first probe trial conducted $24 \mathrm{~h}$ after the completion of acquisition training, wildtype and mutant mice did not differ in the time spent or number of crosses over a target area $2 \times$ the platform diameter, signifying that the memory for the target platform was initially equivalent in both genotypes $(P>0.05$; Fig. 3B,C). In this probe trial, wild-type and mutant mice also displayed a greater amount of time (main effect of platform location: $\left.F_{(1,14)}=24.7, P<0.001\right)$ and crosses in the target location (main effect of platform location: $F_{(1,14)}=23.4$, $P<0.001)$ than in the averaged analogous nontarget areas $(P<$ 0.05 ; wild-type nontarget: \% time: $3.0 \pm 0.6$, crosses: $1.8 \pm 0.3$; mutant nontarget: \% time: $2.4 \pm 0.4$, crosses: $1.6 \pm 0.2$ ). During the extinction probe trials, Dao1 ${ }^{G 181 R}$ mutant mice demonstrated enhanced extinction rates compared with the wild-type animals. The mutant animals spent less time (main effect of genotype: $\left.F_{(1,14)}=3.7, P<0.05\right)$ and made fewer crosses over the target location (main effect of genotype: $F_{(1,14)}=5.3, P<0.05$ ), particularly on the fourth and fifth probe repeat (days 7 and $9, P<0.05$; Fig. 3B,C). Though extinction of the learned response occurred earlier in the mutant mice, it was demonstrated across trials in both genotypes (wild type: main effect of trial: $\%$ time: $F_{(7,49)}=2.7$, $P<0.05$, crosses: $F_{(7,49)}=5.2, P<0.001$; mutant: main effect of trial: \% time: $F_{(7,49)}=4.6, P<0.001$, crosses: $\left.F_{(7,49)}=6.4, P<0.001\right)$. Swim speed, floating, and thigmotaxis time did not differ between genotypes during the extinction phase (main effect of genotype: swim speed: $F_{(1,14)}=0.8, P=0.4$, floating time: $F_{(1,14)}=0.2, P=0.7$, thigmotaxis time: $\left.F_{(1,14)}=0.2, P=0.7\right)$. Additionally, comparisons were made between mutant animals that received several extinc- tion sessions and control mutant animals given a single probe trial on day 9. A greater time $(P<0.05)$ and number of crosses in the target area $(P<0.01)$ were observed in the control mutant mice, indicating that Dao1 ${ }^{G 181 R}$ mutant animals exhibit a facilitation in extinction rather than an impairment in memory duration.

\section{The effects of D-serine treatments on extinction learning}

To confirm that a loss of DAO activity produces an increase in the extinction of a learned response, D-serine treatments were given during the probe sessions to wild-type $\mathrm{C} 57 \mathrm{BL} / 6 \mathrm{~J}$ mice. In the first probe trial following acquisition training, a similar amount of time and number of crosses over an area $2 \times$ the platform diameter was observed in saline-injected and D-serine-injected mice, suggesting that the initial memory for the platform location was comparable in each group $(P>0.05$; Fig. $4 \mathrm{~A}, \mathrm{~B})$. Accordingly, both treatment groups spent more time (main effect of platform location: $F_{(1,15)}=$ 22.6, $P<0.001$ ) and made more crosses over the target area (main effect of platform location: $\left.F_{(1,15)}=33.3, P<0.001\right)$ than in the averaged analogous nontarget locations during the first probe trial $(P<0.05$; saline nontarget: \% time: $3.7 \pm 0.7$, crosses: $1.7 \pm 0.3$; D-serine nontarget: \% time: $3.2 \pm 0.5$, crosses: $2.0 \pm 0.3)$. In the extinction probe sessions, D-serine-treated animals displayed an enhancement in extinction, as measured by the reduced time spent (main effect of genotype: $F_{(1,15)}=6.8, P<0.05$ ) and lower frequency of crosses over the target platform area (main effect of genotype: $F_{(1,15)}=7.9, P<0.05$; Fig. 4A,B). Compared with salinetreated mice, animals given D-serine had a reduction in the amount of time spent in the target location on days $3,5,9$, and $15(P<0.05)$, and crossed the platform area less often on days 9 and $15(P<0.05)$. Though greater in the D-serine-injected mice, extinction was progressively demonstrated across probe sessions in both treatment groups (saline: main effect of trial: $\%$ time: $F_{(7,56)}=$ 4.3, $P<0.001$, crosses: $F_{(7,56)}=5.7, P<0.001 ;$ D-serine: main effect of trial: \% time: $F_{(7,49)}=6.7, P<0.001$, crosses: $F_{(7,49)}=7.1, P<$ 0.001). Additionally, D-serine-treated animals that received a single extinction session on day 9 had a greater percentage of time $(P<0.01)$ and number of crosses over the target location $(P<$ 0.001) compared with mice that received multiple extinction sessions. This indicates that the effects of D-serine were specifically related to extinction rather than forgetting over the passage of 
A
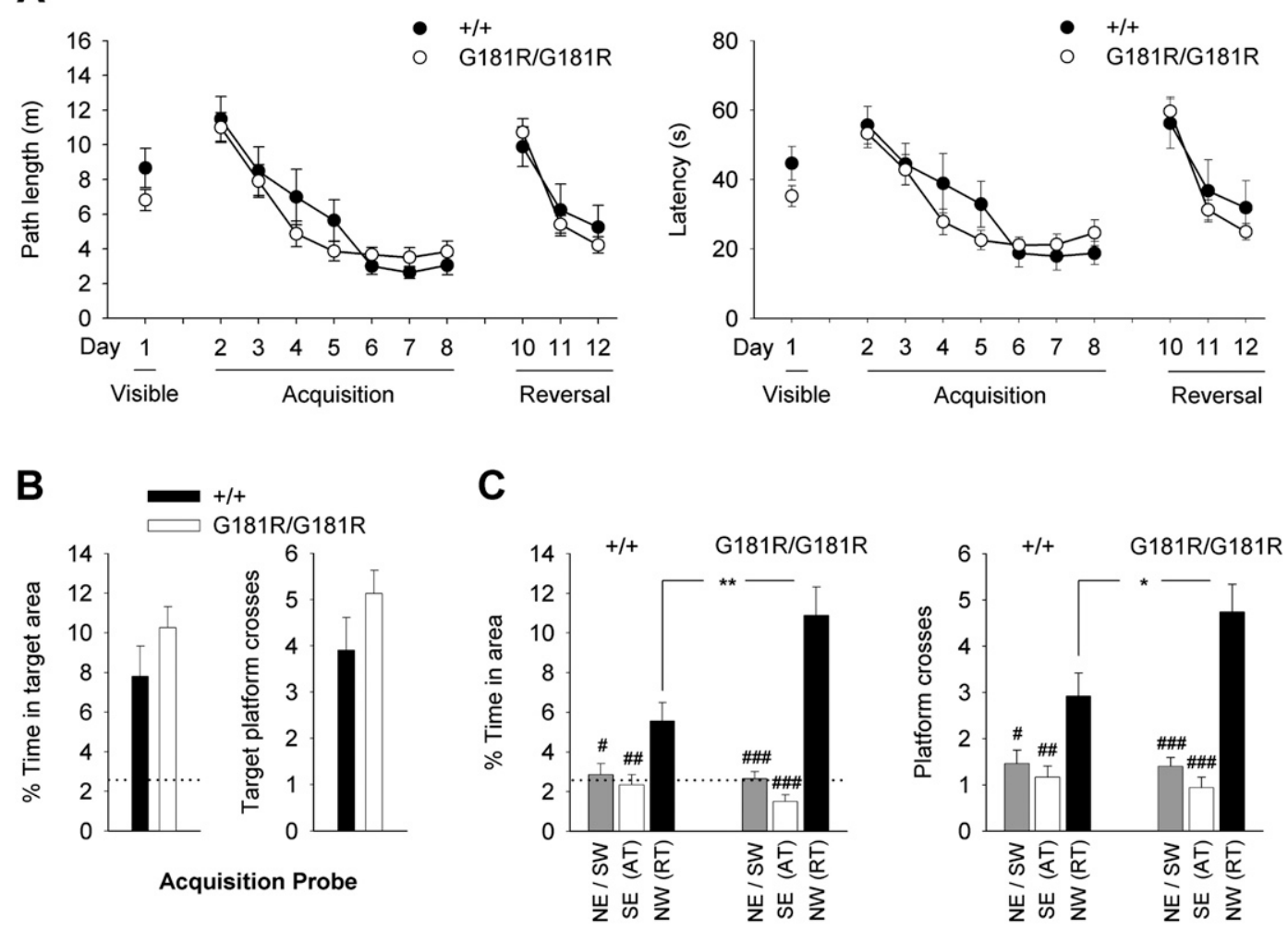

Reversal Probe

Figure 2. $D a 01^{G 181 R}$ mutant mice have improved reversal memory in the MWM task. The path length ( $A$, left panel) and latency $(A$, right panel) to reach a target platform were examined in wild-type $(+/+)$ and mutant (G181R/G181R) mice during a visible platform session (day 1$)$, an acquisition training phase (days 2-8), and a reversal training phase (days 10-12). In the acquisition (B) and reversal (C) probe trials, the percentage of time spent (left panels) and the number of crosses (right panels) over the target area were measured in wild-type and mutant animals. The dashed line represents chance level, corresponding to the ratio of the target area to the total pool area (2.6\%). Platform locations include the reversal target (RT) in the NW quadrant, the acquisition target (AT) in the SE quadrant, and the nontarget areas in the NE and SW quadrants. $n=11$ wild types and 15 mutants; ${ }^{*} P<0.05,{ }^{* *} P<0.01$ compared with wild-type mice within the same platform location; $\# P<0.05, \# \# P<0.01$, \#\#\#P<0.001 compared with the reversal target within the same genotype.

time. In a control experiment conducted on a different cohort of mice, saline-treated and D-serine-treated mice did not express a quadrant bias or abnormalities in swimming behavior (Table 1, right column). Furthermore, D-serine treatments did not affect performance in a visible platform session (Table 1, right column), indicating that D-serine does not impair motor coordination, vision, or search motivation.

\section{Absence of DAO activity affects extinction of contextual fear memory}

Dao1 ${ }^{G 181 R}$ mice were examined in a fear-conditioning paradigm to determine whether our results could extend to another hippocampus-dependent task with different sensory, motivational, and performance requirements. In fear conditioning experiments, the hippocampus is known to be required for the formation and retrieval of context-fear associations, while the amygdala is necessary for conditioning and recall of contextual and cued/tone associations (Holland and Bouton 1999). An assessment of freezing time in the training phase revealed that the Dao1 ${ }^{G 181 R}$ mutation did not produce any nonspecific effects on fear conditioning, as no differences in freezing time were observed during the 2-min baseline activity period, the 30-sec auditory tone exposure, or the 30-sec interval following shock presentation ( $P$ $>0.05$; Fig. $5 \mathrm{~A}$ ). In subsequent sessions, context- and tone-shock associations were evaluated, in which contextual freezing re- sponses were normalized to the baseline activity period, while tone-freezing responses were relative to the pretone period and assessed in an altered context. Wild-type and mutant mice reexposed $24 \mathrm{~h}$ later to the training context did not demonstrate differing freezing responses, indicating a similar learning of the context-shock association ( $P>0.05$; Fig. 5B). However, when the animals were exposed to the context in repeated extinction trials, the Dao1 ${ }^{G 181 R}$ mutant mice demonstrated an enhanced extinction rate (main effect of genotype: $F_{(1,29)}=4.6, P<0.05$ ) that was especially significant on the second exposure (day $3, P<0.05$; Fig. $5 \mathrm{~B})$. Contextual extinction across trials was present earlier in mutant animals (main effect of trial: $F_{(4,64)}=3.9, P<0.01$ ) but also eventually occurred in wild-type animals (main effect of trial: $\left.F_{(4,52)}=6.6, P<0.001\right)$. Supporting the interpretation of facilitated fear extinction, the control mutant group exposed to the context only on day 7 showed a greater freezing time than did mice given several extinction trials $(P<0.05)$. In contrast, the tone-shock association and its extinction were not significantly altered in $D a o 1^{G 181 R}$ mutant mice compared with wild-type littermates $(P>0.05$; Fig. $5 C)$. Since altered pain sensitivity can potentially influence performance in fear conditioning tests (Clapcote et al. 2005), the tail-flick assay was used to examine antinociceptive responses in the Dao1 $1^{G 181 R}$ mice. Latencies following immersion in hot water were similar in wild-type and mutant mice, suggesting an equivalent pain sensitivity in both 

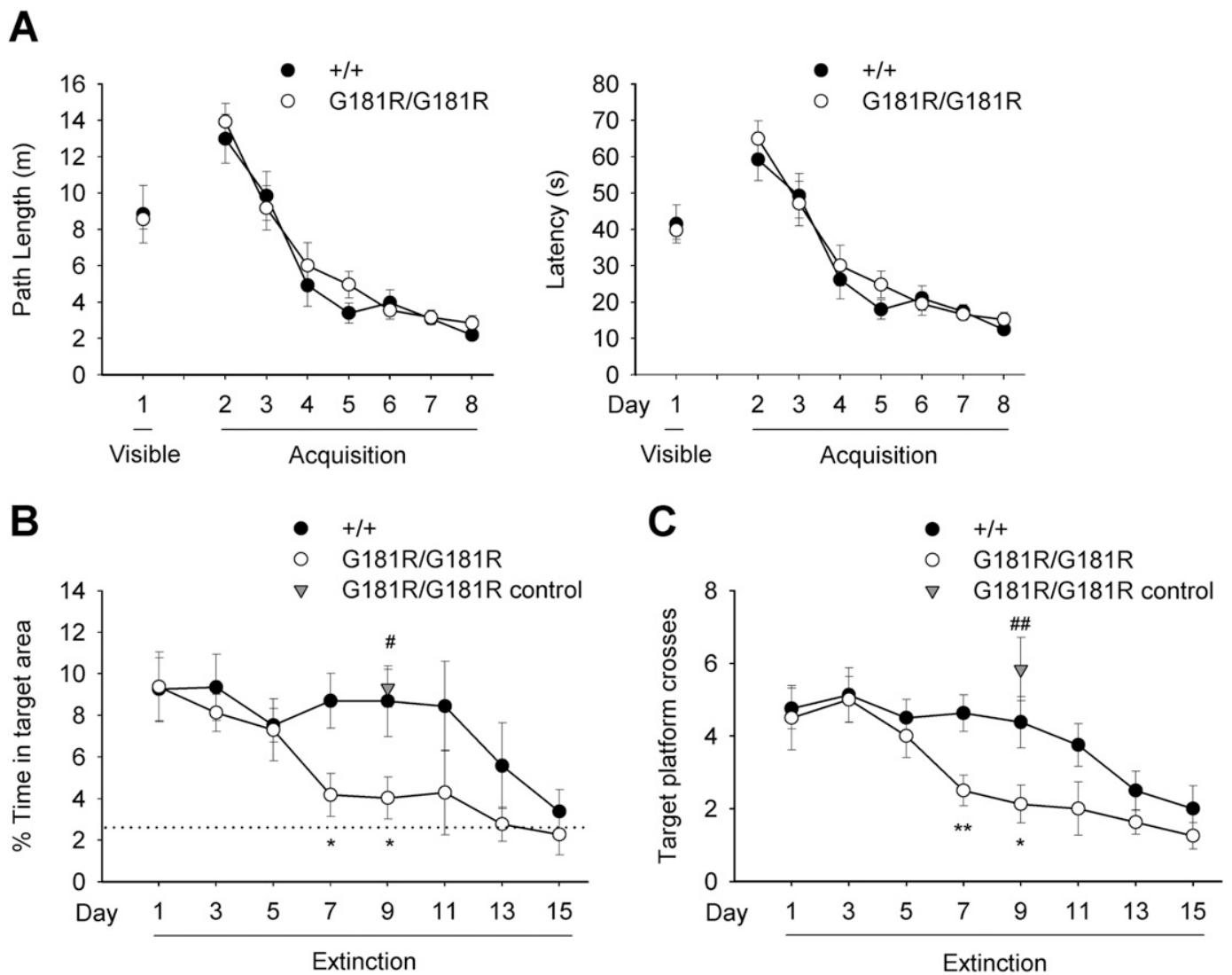

Figure 3. The $D a 01^{G 181 R}$ mutation augments extinction responses in the MWM. The path length $(A$, left panel) and latency $(A$, right panel) to attain a target platform were evaluated in wild-type (+/+) and mutant (G181R/G181R) mice during the visible platform session (day 1$)$ and acguisition training phase (days 2-8). Multiple probe trials were performed on alternate days (1-15), allowing extinction to be examined in the Dao $1^{G 18}{ }^{R}$ wild-type and mutant mice. In a control group of mutant mice, a probe trial was given only on day 9 . During the probe trials, the time spent $(B)$ and frequency of crosses (C) over the target area were determined. Chance levels are depicted as a dashed line. $n=8$ wild types, 8 mutants, and 6 mutant controls; $* P<0.05$, ** $P<$ 0.01 compared with wild-type mice within the same day; $\# P<0.05$, \#\#P<0.01 compared with mutant mice that received several extinction trials.

genotypes (wild type: $14.6 \pm 1.6 \mathrm{sec}, n=17$; mutant: $13.2 \pm 1.7$ sec, $n=15 ; P>0.05)$.

\section{Discussion}

Diminished DAO function was associated with elevated levels of D-serine in the brain and enhancements in reversal memory and extinction learning in the MWM and contextual fear conditioning procedures. Moreover, pharmacological administration of D-serine substantially accelerated extinction of a learned spatial response in the MWM. These findings indicate that D-serine and decreased DAO activity improves performance under changing conditions, and predict their therapeutic utility for the treatment of psychiatric disorders characterized by cognitive inflexibility and aberrant repetitive behaviors.

DAO inhibition may be a well-tolerated and effective means of modulating D-serine levels and NMDAR glycine site occupancy for clinical applications (Coyle and Tsai 2004; Maekawa et al. 2005a; Davis et al. 2006). Animals that chronically lack DAO activity exhibit normal development, longevity, and reproductive potential (Konno and Yasumura 1983). Furthermore, chronic administration of D-serine at therapeutic doses has not been shown to produce adverse effects in humans

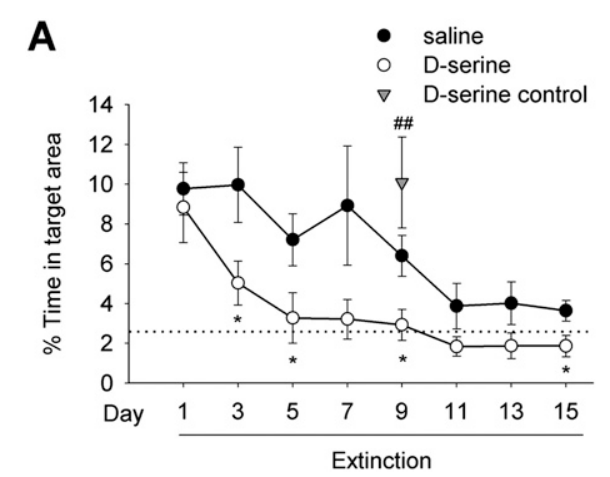

Figure 4. D-serine treatment enhances extinction rates in the MWM. Male C57BL/6] mice were treated with saline or D-serine $(600 \mathrm{mg} / \mathrm{kg})$ before each probe trial (alternate days 1-15), and extinction was evaluated in these mice. Also, a control group of mice were administered D-serine injections in the home cage (alternate days 1-7) and given a probe trial only on day 9. The amount of time spent $(A)$ and number of crosses $(B)$ over the target area were determined for each treatment group. The dashed line indicates chance level. $n=9$ saline, $8 \mathrm{D}$-serine, and $7 \mathrm{D}$-serine controls; ${ }^{*} P<$

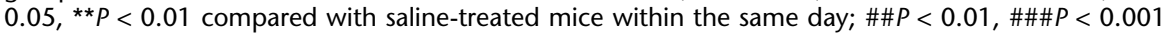
compared with $\mathrm{D}$-serine-treated mice that received several extinction trials. 
(Tsai et al. 1998). However, under conditions that promote excitotoxicity and neuroinflammation, D-serine can potentially compromise neuronal survival through excessive NMDAR activation (Wu et al. 2004; Martineau et al. 2006), suggesting that modest rises in D-serine, as observed following DAO reduction, may be advantageous over dramatic increases. Though D-serine elevations in Dao1 ${ }^{G 181 R}$ mutant mice were shown to be greatest in the cerebellum, as expected based on DAO expression patterns (Moreno et al. 1999), increases were also demonstrated in the hippocampus, an area crucial to the behavioral tasks studied (Whishaw and Tomie 1997; Holland and Bouton 1999). Previous reports have indicated more subtle D-serine increases in the forebrain of Dao1 $1^{G 181 R}$ mutant mice (Hashimoto et al. 1993), but this difference may be related to background mouse strain. Importantly, reduced DAO activity in mutant mice produced increases in D-serine that enhanced NMDAR function (Hashimoto et al. 1993; Wake et al. 2001; Almond et al. 2006) without producing functional changes in $\left[{ }^{3} \mathrm{H}\right]$-D-serine reuptake or alterations in the expression of proteins relevant to NMDAR signaling, including NR1, serine racemase, glycine transporter 1, and alanine-serinecysteine transporter 1 (Almond et al. 2006). This suggests a lack of obvious compensatory changes in the Dao1 ${ }^{\text {G181R }}$ mice. Hence, these animals may be useful preclinical models for the study of behavioral endophenotypes specifically related to diminished DAO function.

This study is the first to demonstrate that inactivation of DAO leads to improved behavioral flexibility in response to changing environmental contingencies. In the reversal phase of the MWM, memory for the novel platform location was selectively enhanced in Dao1 ${ }^{G 181 R}$ mutant mice. Prior studies investigating genetically modified and wild-type mice have attributed performance in the reversal MWM task to the capacity for cognitive flexibility, i.e., the ability to simultaneously inhibit a previously acquired spatial navigation strategy and develop a new strategy (Malleret et al. 1999; Duffy et al. 2008). Deficits in reversal learning and perseveration have been reported in both rodents and humans given NMDAR antagonists (Krystal et al. 2000; van der Meulen et al. 2003; Andersen and Pouzet 2004), as well as in rats with lesions to the fimbria-fornix or hippocampus (Whishaw and Tomie 1997). Acute administration of D-serine, on the other hand, has been shown to enhance reversal learning in the MWM in wildtype mice (Duffy et al. 2008) and in rats treated with the NMDAR antagonist phencyclidine (Andersen and Pouzet 2004). Additionally, nitric oxide (NO) has been shown to promote DAO function and suppress serine racemase activity, and antagonism of NO synthase was found to rescue phencycline-induced impairments in MWM reversal learning (Shoji et al. 2006; Wass et al. 2008). By directly targeting DAO function, our study indicates that chronically enhanced D-serine levels can also promote appropriate reversal behaviors, and suggests that DAO inhibition may attenuate symptoms of cognitive inflexibility, such as those commonly observed in patients with schizophrenia (Pantelis et al. 1999). Indeed, a clinical study demonstrated that D-serine administration improved the performance of schizophrenic individuals in the Wisconsin card sorting task, a widely used measure of flexibility (Tsai et al. 1998).

Extinction is regarded as a distinct form of learning that acts to suppress, but not erase, previously learned responses (Davis et al. 2006). Like other forms of learning, extinction has been shown to depend on glutamate NMDAR-associated signaling pathways, gene expression, and protein synthesis (Davis et al. 2006). A growing body of evidence indicates that the NMDAR glycine site may be particularly important in mediating the extinction of fear memory (Davis et al. 2006; Norberg et al. 2008). The partial NMDAR agonist D-cycloserine has been shown to facilitate fear extinction and exposure therapy, though it is not yet clear whether the improvements are related to an increase of NMDAR function during the extinction process (Ressler et al. 2004; Ledgerwood et al. 2005; Norberg et al. 2008). Here, we show that elevated D-serine can accelerate extinction in spatial and fearbased tasks. The improvements were demonstrated to be specifically related to an increase in extinction learning rather than to a deficit in memory duration. Furthermore, the ability of acute D-serine treatments to replicate these findings in wild-type mice indicates this behavioral phenotype is not likely the result of potential abnormalities due to increased D-serine levels during development. Also, facilitated extinction in Dao1 ${ }^{G 181 R}$ mutant mice could not be attributed to changes in motivation or anxiety, as no differences were observed in the incentive to find a visible platform, or in behaviors indicative of anxiety, such as thigmotaxis and baseline freezing. Although we did not detect differing responses in an assessment of antinociception, mutant mice have previously been reported to have elevations in pain sensitivity

A

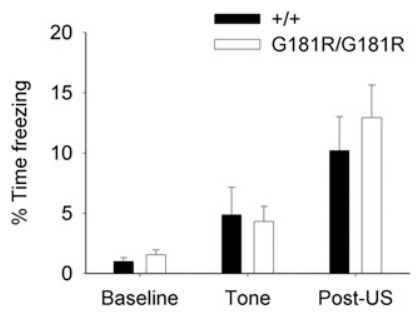

B
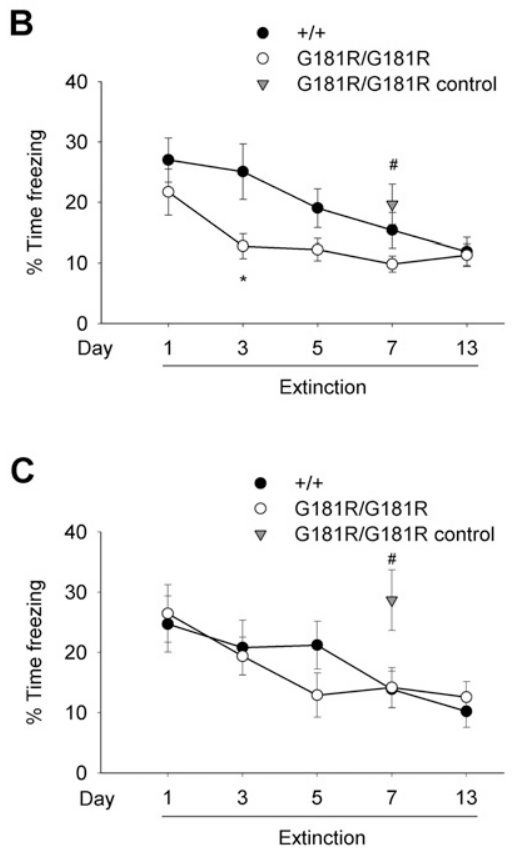

Figure 5. Loss of DAO activity facilitates the extinction of contextual fear memory. Freezing responses in wild-type $(+/+)$ and $D a 01^{\mathrm{Cl} 181 \mathrm{R}}$ mutant (G181R/G181R) animals were measured during a training session (A) that contained a baseline activity period, followed by a $30-\mathrm{sec}$ exposure to an auditory tone that coterminated with a foot shock (US). The percentage time spent freezing to the context $(B)$ and to the tone in an altered context $(C)$ was evaluated in wild-type and mutant mice during the extinction trials (days $1,3,5,7$, and 13). Freezing responses were also measured in a control group of mutants exposed to the context and tone on day 7 only. $n=14$ wild types, 17 mutants, and 17 mutant controls; ${ }^{*} P<$ 0.05 compared with wild-type mice within the same day; $\# P<0.05$ compared with mutant mice that received multiple extinction trials. 
(Wake et al. 2001), which might bias toward the persistence of a fear response.

Genetic perturbation of DAO activity specifically improved reversal memory and extinction without altering performance during the acquisition trials. Activation of the NMDAR glycine site has been shown to be necessary for the acquisition and memory retrieval of a single platform location (Watanabe et al. 1992). However, the ability of glycine site activators to potentiate this type of spatial learning and memory beyond normal capacity remains controversial (Pitkänen et al. 1995; Andersen and Pouzet 2004; Maekawa et al. 2005b; Duffy et al. 2008; Zhang et al. 2008), and discrepancies may reflect different procedural demands, dosing regimes, or species. In the acquisition phase of our study, animals were trained to achieve asymptotic performance in order to assess reversal learning and extinction from a common baseline. Consequently, we cannot preclude a possible enhancement of acquisition by D-serine under some conditions, and others have shown that elevated D-serine can enhance acquisition of spatial learning (Maekawa et al. 2005b). Regardless, we demonstrate that elevations in D-serine are not required during acquisition sessions in order to improve extinction learning, further supporting a vital role in adaptive behaviors necessary for changing contingencies.

Activation of NMDARs is critically involved in the synaptoplastic processes underlying the acquisition of novel behaviors (Nicoll 2003). Recent studies suggest that behavioral alterations in response to changing environmental conditions are also dependent on NMDAR activity (Sotres-Bayon et al. 2007; Duffy et al. 2008; Nicholls et al. 2008), though the neurocellular mechanisms are unclear. Activation of pre-existing circuits encoding memory traces renders them subject to modification, a process termed reconsolidation (Tronson and Taylor 2007). NMDAR antagonists, including compounds that target NR2B receptors prevent the induction of memory lability (Ben Mamou et al. 2006). Consequently, increased D-serine may augment the propensity for NMDAR-dependent reconsolidation. NMDAR-mediated longterm depression (LTD) is one form of synaptic plasticity that may contribute to behavioral flexibility by facilitating the remodeling of labile circuits. Alternatively, LTD may facilitate learning under changing environmental conditions by suppressing the expression of previously encoded memory traces. In either case, there is compelling evidence for the role of LTD in behavioral flexibility and inhibition. Transgenic mice that exhibit deficits in hippocampal LTD demonstrated a parallel disruption in the ability to learn novel platform locations in the MWM (Zeng et al. 2001; Morice et al. 2007; Nicholls et al. 2008) and a deficiency in acquisition and recall of fear extinction (Dalton et al. 2007). Blockade of NMDA-NR2B receptors has been reported to inhibit hippocampal LTD in the adult mouse and has also been found to disrupt behavioral inhibition in a serial reaction task, spatial reversal learning, and fear extinction learning and retention (Higgins et al. 2003; Sotres-Bayon et al. 2007; Duffy et al. 2008). Conversely, mice overexpressing NR2B receptors exhibit better learning and memory in tasks that include extinction of fear associations (Tang et al. 1999). Likewise, exogenous application of D-serine was shown to strongly enhance NR2B-dependent LTD in rodent hippocampal slices in vitro (Duffy et al. 2008; Zhang et al. 2008). Finally, the propensity for LTD has been shown to increase with exposure to novel environments and when salient environmental cues are relocated (Manahan-Vaughan and Braunewell 1999; Kemp and Manahan-Vaughan 2004).

In conclusion, elevated D-serine and genetic inactivation of $\mathrm{DAO}$ function ameliorated cognitive flexibility and inhibitory learning in the MWM and in a contextual fear-conditioning task. Growing evidence indicates that reduced occupancy of the NMDAR glycine binding site may be involved in the pathophys- iology of schizophrenia, and activators that target this site may have therapeutic potential (Coyle and Tsai 2004; Millan 2005). Furthermore, modulation of the NMDAR glycine site has also been proposed to benefit extinction and exposure therapy, which are used to treat several psychopathologies, including obsessivecompulsive disorder and post-traumatic stress syndrome (Ressler et al. 2004; Norberg et al. 2008). The improvement of adaptive responses through the inhibition of DAO activity may be of substantial clinical utility for the treatment of these and other psychiatric illnesses involving an inability to attenuate persistent maladaptive behaviors.

\section{Materials and Methods}

\section{Subjects}

The Dao1 $1^{G 181 R}$ mice were obtained from the Konno laboratory that initially identified this spontaneous missense mutation (glycine to arginine at amino acid 181) in the Dao1 gene of the ddY strain, resulting in a complete loss of DAO activity (Konno and Yasumura 1983; Sasaki et al. 1992). The Dao1 ${ }^{G 181 R}$ mutation was transferred onto a C57BL/6J genetic background using a marker-assisted speed congenic strategy (Wong 2002). The resultant Dao1 $1^{G 181 R}$ mice contained $>99 \%$ of the C57BL/6J genome after six generations of backcrossing. Experimental subjects were then bred from heterozygous intercrosses of $D a 01^{G 181 R}$ mice in the animal colony at the Samuel Lunenfeld Research Institute (Toronto, Canada). Animals carrying the Dao1 $1^{G 181 R}$ mutation were genotyped using a PCR-amplicon restriction endonuclease protocol that involved the amplification of a 263-bp PCR product (5'-TGATGTACGAAGCTGGAGGACA-3' and 5'-TGTA GTGGCACCAGCTTT-3'), which lacked an HpaII (Fermentas) restriction site in the homozygous state. Male C57BL/6J mice were purchased from the Jackson Laboratory (Bar Harbor, ME, USA) and were acclimatized to the animal colony for $\geq 1$ wk prior to testing.

Groups of three to five littermates were housed by sex in polycarbonate cages and given ad libitum sterile food (Purina mouse chow) and water. The vivarium was maintained under a controlled temperature $\left(21^{\circ} \mathrm{C} \pm 1^{\circ} \mathrm{C}\right)$ and humidity $(50 \%-60 \%)$, with a 12-h diurnal cycle (lights on: 0700-1900 h). All animal procedures strictly followed the requirements of the Province of Ontario Animals for Research Act 1971 and the Canadian Council on Animal Care.

\section{High-performance liquid chromatography}

The high-performance liquid chromatography (HPLC) procedure was adapted from a previously described protocol (Grant et al. 2006). Brain samples were homogenized in 5 vol of ice-cold double-distilled water. An aliquot was mixed with 100\% methanol to give a final dilution of $60 \times$ and then centrifuged at $12,000 \mathrm{~g}$ for $4 \mathrm{~min}$ at $4^{\circ} \mathrm{C}$. A $5 \mu \mathrm{L}$ aliquot of the supernatant was mixed with $5 \mu \mathrm{L}$ of the derivatizing reagent $(2 \mathrm{mg}$ N-isobutyryl-L-cysteine and $1 \mathrm{mg}$ o-phthaldialdehyde dissolved in $0.1 \mathrm{~mL}$ methanol, followed by addition of $0.9 \mathrm{~mL} 0.1 \mathrm{M}$ sodium borate buffer), and then was placed into a sample management system (Waters Alliance 2690XE, Waters Corp.). HPLC separation was achieved on a Symmetry C18 column $(4.6 \mathrm{~mm} \times 150 \mathrm{~mm} ; 3.5-\mu \mathrm{m}$ particle diameter) coupled with a guard column of the same stationary phase (Waters Corp.). The column heater was set at $30^{\circ} \mathrm{C}$, and the sample cooler was held at $4^{\circ} \mathrm{C}$. To separate the derivatized amino acids of interest, a gradient was established from equal parts of solvent $\mathrm{A}$ $(850 \mathrm{~mL}$ of $0.04 \mathrm{M}$ sodium phosphate buffer and $150 \mathrm{~mL}$ methanol at $\mathrm{pH} 6.2)$ and $\mathrm{B}(670 \mathrm{~mL}$ of $0.04 \mathrm{M}$ sodium phosphate buffer, $555 \mathrm{~mL}$ methanol and $30 \mathrm{~mL}$ tetrahydrofuran, $\mathrm{pH}$ 6.2) to only solvent $\mathrm{B}$ by $\sim 45 \mathrm{~min}$, with a flow rate of $0.5 \mathrm{~mL} / \mathrm{min}$. The runtime was 60 min for column washout and equilibrium, and 30 min to elute all compounds. A Waters 2475 fluorescence detector (Waters Corp.) was used to quantify the eluted compounds (excitation $344 \mathrm{~nm}$; emission $433 \mathrm{~nm}$ ). 


\section{Chemiluminescent assay}

The procedure for the chemiluminescent assay was modified from a described protocol (Wolosker et al. 1999). Brain samples were homogenized in ice-cold buffer $(50 \mathrm{mM}$ Tris- $\mathrm{HCl}, \mathrm{pH} 8.8,10 \mathrm{mM}$ $\mathrm{KCl}$ ) and then centrifuged at $14,000 \mathrm{~g}$ for $10 \mathrm{~min}$ at $4^{\circ} \mathrm{C}$. From the supernatant, protein concentrations were measured and standardized. Samples were heated at $100^{\circ} \mathrm{C}$ for $20 \mathrm{~min}$ to eliminate endogenous DAO activity and then cooled to $4^{\circ} \mathrm{C}$. Assay buffer $(50 \mu \mathrm{L}$ of $100 \mathrm{mM}$ Tris, $50 \mathrm{mM} \mathrm{NaCl}, \mathrm{pH}$ 8.8) with $0.1 \mathrm{U}$ horseradish peroxidase (Biochemika, Sigma), $0.8 \mathrm{nmol}$ luminol (Sigma), and $0.048 \mathrm{nmol}$ flavin adenine dinucleotide (EMD Chemicals Inc.) was added to each sample $(10 \mu \mathrm{L})$. A Veritas Microplate Luminometer (Turner Biosystems Inc.) was used to detect the production of $\mathrm{H}_{2} \mathrm{O}_{2}$ before and after the addition of $0.002 \mathrm{U} R$. gracilis DAO (recombinant courtesy of L. Pollegioni, University of Insubria, Varese, Italy). Triplicates of each sample were measured, and the content of D-serine was quantified using a calibration curve of D-serine standards.

\section{Behavioral studies}

Behavioral testing was performed during the light phase between 1100 and $1700 \mathrm{~h}$ on experimentally naïve mice that were 11-16 wk old. Experiments were sex-balanced, except where stated. Since no sex differences were found in the measured behaviors, male and female data were pooled for greater subject numbers. Experimenters were blind to genotype. Subjects were handled for $2 \mathrm{~min} /$ $\mathrm{d}$ on each of the five consecutive days prior to testing. During the experimental days, mice were initially left undisturbed in the room for $30 \mathrm{~min}$ before the start of the procedure to allow for acclimatization.

\section{Morris water maze}

The Morris water maze (MWM) consisted of a white Plexiglas, cylindrical pool (1.85-m diameter) that was filled with opaque water $\left(26^{\circ} \mathrm{C} \pm 1{ }^{\circ} \mathrm{C}\right)$, as described by Duffy et al. (2008). The pool was arbitrarily divided into four equal quadrants: northeast, northwest, southeast, and southwest. The circular escape platform (10-cm diameter) was made of clear Plexiglas. Distal visual cues were fixed on each wall $\sim 1 \mathrm{~m}$ from the pool edge. Activity in the water maze was recorded using a CCD camera on the ceiling above the center of the pool attached to an automated tracking system (HVS Image Ltd.) that extracted and stored the $x-y$ coordinates of the subject every $0.01 \mathrm{sec}$. The HVS Water 2020 software (HVS Image Ltd.) was used to establish experimental parameters and analyze performance. Behavioral measures in the MWM included latency to target (sec), path length (m), thigmotaxis (percent time within $12.5 \mathrm{~cm}$ of the pool wall), swim speed $(\mathrm{cm} / \mathrm{sec})$, floating (percent time), number of platform crosses, and percent time within the target area.

Each MWM procedure began with a 1-d stationary visible platform task. Mice were given 4 trials with an $\sim 1$-h intertrial interval (ITI). In each trial, mice were released facing the pool wall from one of four pseudorandomized locations $(\mathrm{N}, \mathrm{S}, \mathrm{W}, \mathrm{E})$ at the pool periphery. The platform was at the center of the target quadrant (SE) and $25 \mathrm{~cm}$ from the pool wall. In the visible trials, the platform was raised $0.5 \mathrm{~cm}$ above the water surface and demarcated with a $10-\mathrm{cm}$ vertical pole. The maximum duration for a platform search was $90 \mathrm{sec}$. Animals that found the platform remained on it for an additional $15 \mathrm{sec}$, whereas unsuccessful animals were assigned a 90-sec latency and gently placed onto the platform for $15 \mathrm{sec}$. The acquisition phase began $1 \mathrm{~d}$ later, and lasted for seven consecutive days ( 4 trials/d, $1 \mathrm{~h}$ ITI). Each day was performed similarly to the visible platform task, except the platform was now submerged $\sim 1 \mathrm{~cm}$ below the surface of the water (hidden) in the SE quadrant. Retention of spatial memory was assessed in a 60 -sec probe trial that occurred $24 \mathrm{~h}$ after the last acquisition trial. In the probe trial, the platform was removed and mice were released from the point furthest (NW) from the former platform location. Performance in the probe trial was quantified by examining the percentage of time spent and number of crosses over an area that was twice the platform diameter, centered over its former location.

\section{Reversal learning and memory}

The reversal experiments entailed three additional days of training (four trials/d, $1 \mathrm{~h}$ ITI) that began $1 \mathrm{~d}$ after the acquisition probe. Reversal trials were conducted as described in the above acquisition phase, with the exception that the platform was located in the center of the NW (opposite) quadrant. Memory for the new platform location was examined in a 60 -sec reversal probe that was assessed $24 \mathrm{~h}$ after the last reversal trial (SW release point).

\section{Extinction}

The extinction trials were performed as described in the acquisition probe, and occurred on the following days after the last acquisition trial: $1,3,5,7,9,11,13$, and 15 (48 h ITI). To verify that the Dao1 ${ }^{G 181 R}$ mutation or D-serine treatments did not impair memory duration, control groups of Dao1 $1^{G 181 R}$ mutant and Dserine-injected mice were tested for the first time $9 \mathrm{~d}$ after the completion of acquisition training. The D-serine-treated control group was injected in the home cage on the same days as those mice exposed to multiple probe trials.

\section{Fear conditioning}

Contextual and cued fear conditioning were conducted as previously described (Clapcote et al. 2005; Young et al. 2008). The fear conditioning apparatus (MED Associates Inc.) consisted of four test chambers $(25 \mathrm{~cm}$ height $\times 30 \mathrm{~cm}$ width $\times 25 \mathrm{~cm}$ length $)$ that each had a grid floor and were connected to a shock generator, amplifier, and speaker. Experimental parameters were controlled by automated fear conditioning software (FreezeFrame v. 1.6e, Actimetrics) that also recorded freezing activity (presented as a percentage of total time). In the training phase, each chamber had a white curtain covering the front exterior and was cleaned with $70 \%$ ethanol that left an odor. All surfaces in contact with test subjects were carefully dried, and odor cues were placed on a surface that was unattainable by the animals. The training phase began with a 2-min period in the chamber to monitor baseline activity. Afterward, a 30-sec auditory tone was delivered $(3600 \mathrm{~Hz}$, $95 \mathrm{~dB}$ ), and in the last 2 sec of tone presentation, a continuous foot shock $(0.75 \mathrm{~mA}$ scrambled) was administered. The animals were given an additional 30-sec period (post-US) before being returned to their home cages. Freezing to the context was assessed for $5 \mathrm{~min}$ without tone or foot shock on the following days after training: 1 (24 h later), 3, 5, 7, and 13. The fear conditioning extinction sessions were conducted over days in order to resemble the extinction procedure completed in the MWM. The percentage of time freezing specifically to the context was calculated for each subject [\% time freezing to context $=\%$ time freezing during context exposure - \% time freezing during training baseline period], and these values were averaged for each genotype (Valentinuzzi et al. 1998). Freezing response to the tone cue was measured in an altered chamber $2 \mathrm{~h}$ after each contextual freezing session. Ventilation of the testing room, in addition to careful cleaning and drying of the chambers during this delay eliminated the odor used in the contextual freezing session. For the tone test, the sensory environment of the chamber was altered using a $1 \%$ acetic acid odor, a smooth white Plexiglas floor, a black curtain on the front exterior, and a clear Plexiglas insert that gave the interior of the chamber a prism shape. These chamber alterations did not affect the tone frequency but did reduce the tone amplitude by $2 \mathrm{~dB}$. Animals were placed in the chamber and given $3 \mathrm{~min}$ to explore (pretone) followed by a 3-min exposure to the tone. The percentage of time freezing specifically to tone was determined for each subject [\% time freezing to tone $=\%$ time freezing during tone exposure - \% time freezing during pretone period], and these values were then averaged for each genotype (Graves et al. 2003).

\section{Tail-flick assay}

The warm water tail-flick test was performed as previously described (Bohn et al. 2002). Mice were carefully held by the examiner, and $\sim 3 \mathrm{~cm}$ of the distal end of their tails were immersed 
in $50^{\circ} \mathrm{C}$ water. The latency to respond to the thermal stimulus by removing the tail from the warm water (tail flick) was measured with a stopwatch and used to evaluate antinociception.

\section{Drugs}

In the drug treatment experiment (Fig. 4), D-serine (Sigma) was administered $30 \mathrm{~min}$ before each probe trial to male C57BL/6J mice. No treatments were given during visible or acquisition training. D-serine $(600 \mathrm{mg} / \mathrm{kg})$ was dissolved in $0.9 \% \mathrm{NaCl}$ saline solution and injected subcutaneously at a volume of $10 \mathrm{~mL} / \mathrm{kg}$. The dose of D-serine was based on previous work with this compound in the MWM (Duffy et al. 2008).

\section{Statistical analysis}

Statistical analyses were completed using Statistica (Statsoft Inc.). Biochemical and behavioral data were analyzed using oneway, two-way, or repeated-measures ANOVA with the appropriate between- and within-subjects factors. Significant main effects or interactions were followed by Fisher's least significant difference (LSD) post-hoc comparisons. Significance was set at $P<0.05$.

\section{Acknowledgments}

V.L. was supported by Natural Sciences and Engineering Research Council (NSERC, Canada) studentship. J.C.R. is a Canadian Research Council (CRC) chair. The research was supported by the Canadian Institutes of Health Research (CIHR) and the United States National Institutes of Health (P01AG12411). We thank Gail Rauw and Edward Weiss for expert technical assistance.

\section{References}

Almond, S.L., Fradley, R.L., Armstrong, E.J., Heavens, R.B., Rutter, A.R. Newman, R.J., Chiu, C.S., Konno, R., Hutson, P.H., and Brandon, N.J. 2006. Behavioral and biochemical characterization of a mutant mouse strain lacking D-amino acid oxidase activity and its implications for schizophrenia. Mol. Cell. Neurosci. 32: 324-334.

Andersen, J.D. and Pouzet, B. 2004. Spatial memory deficits induced by perinatal treatment of rats with PCP and reversal effect of D-serine. Neuropsychopharmacology 29: 1080-1090.

Bauer, D., Hamacher, K., Bröer, S., Pauleit, D., Palm, C., Zilles, K., Coenen, H.H., and Langen, K.J. 2005. Preferred stereoselective brain uptake of D-serine-a modulator of glutamatergic neurotransmission. Nucl. Med. Biol. 32: 793-797.

Ben Mamou, C., Gamache, K., and Nader, K. 2006. NMDA receptors are critical for unleashing consolidated auditory fear memories. Nat Neurosci. 9: 1237-1239.

Bohn, L.M., Lefkowitz, R.J., and Caron, M.G. 2002. Differential mechanisms of morphine antinociceptive tolerance revealed in $\beta$-arrestin-2 knockout mice. J. Neurosci. 22: 10494-10500.

Chumakov, I., Blumenfeld, M., Guerassimenko, O., Cavarec, L., Palicio, M. Abderrahim, H., Bougueleret, L., Barry, C., Tanaka, H., La Rosa, P., et al. 2002. Genetic and physiological data implicating the new human gene G72 and the gene for D-amino acid oxidase in schizophrenia. Proc. Natl. Acad. Sci. 99: 13675-13680.

Clapcote, S.J., Lazar, N.L., Bechard, A.R., and Roder, J.C. 2005. Effects of the rd1 mutation and host strain on hippocampal learning in mice. Behav. Genet. 35: 591-601.

Clements, J.D. and Westbrook, G.L. 1991. Activation kinetics reveal the number of glutamate and glycine binding sites on the $N$-methyl-Daspartate receptor. Neuron 7: 605-613.

Coyle, J.T. and Tsai, G. 2004. The NMDA receptor glycine modulatory site: A therapeutic target for improving cognition and reducing negative symptoms in schizophrenia. Psychopharmacology 174: 3238.

Dalton, G.L., Wang, Y.T., Floresco, S.B., and Phillips, A.G. 2007. Disruption of AMPA receptor endocytosis impairs the extinction, but not acquisition of learned fear. Neuropsychopharmacology 33: 2416-2426.

Davis, M., Ressler, K., Rothbaum, B.O., and Richardson, R. 2006. Effects of D-cycloserine on extinction: Translation from preclinical to clinical work. Biol. Psychiatry 60: 369-375.

Duffy, S., Labrie, V., and Roder, J.C. 2008. D-Serine augments NMDA-NR2B receptor-dependent hippocampal long-term depression and spatial reversal learning. Neuropsychopharmacology 33: 1004-1018.
Foltyn, V.N., Bendikov, I., De Miranda, J., Panizzutti, R., Dumin, E., Shleper, M., Li, P., Toney, M.D., Kartvelishvily, E., and Wolosker, H. 2005. Serine racemase modulates intracellular D-serine levels through an $\alpha, \beta$ elimination activity. J. Biol. Chem. 280: 1754-1763.

Fuchs, S.A., Berger, R., Klomp, L.W., and de Koning, T.J. 2005. D-amino acids in the central nervous system in health and disease. Mol. Genet. Metab. 85: 168-180.

Grant, S.L., Shulman, Y., Tibbo, P., Hampson, D.R., and Baker, G.B. 2006. Determination of D-serine and related neuroactive amino acids in human plasma by high-performance liquid chromatography with fluorimetric detection. J. Chromatogr. B Analyt. Technol. Biomed. Life Sci. 844: $278-282$.

Graves, L.A., Heller, E.A., Pack, A.I., and Abel, T. 2003. Sleep deprivation selectively impairs memory consolidation for contextual fear conditioning. Learn. Mem. 10: 168-176.

Hashimoto, A., Nishikawa, T., Konno, R., Niwa, A., Yasumura, Y., Oka, T., and Takahashi, K. 1993. Free D-serine, D-aspartate and D-alanine in central nervous system and serum in mutant mice lacking $\mathrm{D}$-amino acid oxidase. Neurosci. Lett. 152: 33-36.

Hashimoto, K., Fukushima, T., Shimizu, E., Komatsu, N., Watanabe, H., Shinoda, N., Nakazato, M., Kumakiri, C., Okada, S., Hasegawa, H., et al. 2003. Decreased serum levels of D-serine in patients with schizophrenia: Evidence in support of the N-methyl-D-aspartate receptor hypofunction hypothesis of schizophrenia. Arch. Gen. Psychiatry 60: $572-576$.

Hashimoto, K., Engberg, G., Shimizu, E., Nordin, C., Lindstrom, L.H., and Iyo, M. 2005. Reduced D-serine to total serine ratio in the cerebrospinal fluid of drug naïve schizophrenic patients. Prog. Neuropsychopharmacol. Biol. Psychiatry 29: 767-769.

Heresco-Levy, U., Javitt, D.C., Ebstein, R., Vass, A., Lichtenberg, P., Bar, G., Catinari, S., and Ermilov, M. 2005. D-serine efficacy as add-on pharmacotherapy to risperidone and olanzapine for treatmentrefractory schizophrenia. Biol. Psychiatry 57: 577-585.

Higgins, G.A., Ballard, T.M., Huwyler, J., Kemp, J.A., and Gill, R. 2003. Evaluation of the NR2B-selective NMDA receptor antagonist Ro 631908 on rodent behaviour: Evidence for an involvement of NR2B NMDA receptors in response inhibition. Neuropharmacology 44: 324-341.

Holland, P.C. and Bouton, M.E. 1999. Hippocampus and context in classical conditioning. Curr. Opin. Neurobiol. 9: 195-202.

Javitt, D.C. and Zukin, S.R. 1991. Recent advances in the phencyclidine model of schizophrenia. Am. J. Psychiatry 148: 1301-1308.

Johnson, J.W. and Ascher, P. 1987. Glycine potentiates the NMDA response in cultured mouse brain neurons. Nature 325: 529-531.

Kehoe, E.J., Macrae, M., and Hutchinson, C.L. 1996. MK-801 protects conditioned response from extinction in the rabbit nictitating membrane preparation. Psychobiology 24: 127-135.

Kemp, A. and Manahan-Vaughan, D. 2004. Hippocampal long-term depression and long-term potentiation encode different aspects of novelty acquisition. Proc. Natl. Acad. Sci. 101: 8192-8197.

Konno, R. and Yasumura, Y. 1983. Mouse mutant deficient in D-amino acid oxidase activity. Genetics 103: $277-285$

Krystal, J.H., Karper, L.P., Seibyl, J.P., Freeman, G.K., Delaney, R., Bremner, J.D., Heninger, G.R., Bowers Jr., M.B., and Charney, D.S 1994. Subanesthetic effects of the noncompetitive NMDA antagonist, ketamine, in humans. Psychotomimetic, perceptual, cognitive, and neuroendocrine responses. Arch. Gen. Psychiatry 51: $199-214$

Krystal, J.H., Bennett, A., Abi-Saab, D., Belger, A., Karper, L.P., D’Souza, D.C., Lipschitz, D., Abi-Dargham, A., and Charney, D.S. 2000. Dissociation of ketamine effects on rule acquisition and rule implementation: Possible relevance to NMDA receptor contributions to executive cognitive functions. Biol. Psychiatry 47: 137-143.

Ledgerwood, L., Richardson, R., and Cranney, J. 2005. D-cycloserine facilitates extinction of learned fear: Effects on reacquisition and generalized extinction. Biol. Psychiatry 57: 841-847.

Lee, H. and Kim, J.J. 1998. Amygdalar NMDA receptors are critical for new fear learning in previously fear-conditioned rats. J. Neurosci. 18: 8444-8454.

Maekawa, M., Okamura, T., Kasai, N., Hori, Y., Summer, K.H., and Konno, R. 2005a. D-amino-acid oxidase is involved in D-serine-induced nephrotoxicity. Chem. Res. Toxicol. 18: 1678-1682.

Maekawa, M., Watanabe, M., Yamaguchi, S., Konno, R., and Hori, Y. 2005b. Spatial learning and long-term potentiation of mutant mice lacking Damino-acid oxidase. Neurosci. Res. 53: 34-38.

Malleret, G., Hen, R., Guillou, J.L., Segu, L., and Buhot, M.C. 1999. 5-HT1B receptor knock-out mice exhibit increased exploratory activity and enhanced spatial memory performance in the Morris water maze. $J$. Neurosci. 19: 6157-6168.

Manahan-Vaughan, D. and Braunewell, K.H. 1999. Novelty acquisition is associated with induction of hippocampal long-term depression. Proc. Natl. Acad. Sci. 96: 8739-8744. 
Martineau, M., Baux, G., and Mothet, J.P. 2006. D-serine signalling in the brain: Friend and foe. Trends Neurosci. 29: 481-491.

Matsui, T., Sekiguchi, M., Hashimoto, A., Tomita, U., Nishikawa, T., and Wada, K.J. 1995. Functional comparison of D-serine and glycine in rodents: The effects on cloned NMDA receptors and the extracellular concentration. J. Neurochem. 65: 454-458.

Millan, M.J. 2005. N-methyl-D-aspartate receptors as a target for improved antipsychotic agents: Novel insights and clinical perspectives. Psychopharmacology 179: 30-53.

Moreno, S., Nardacci, R., Cimini, A., and Cerù, M.P. 1999. Immunocytochemical localization of D-amino acid oxidase in rat brain. J. Neurocytol. 28: 169-185.

Morice, E., Billard, J.M., Denis, C., Mathieu, F., Betancur, C., Epelbaum, J., Giros, B., and Nosten-Bertrand, M. 2007. Parallel loss of hippocampal LTD and cognitive flexibility in a genetic model of hyperdopaminergia. Neuropsychopharmacology 32: 2108-2116.

Mothet, J.P., Parent, A.T., Wolosker, H., Brady Jr., R.O., Linden, D.J., Ferris, C.D., Rogawski, M.A., and Snyder, S.H. 2000. D-serine is an endogenous ligand for the glycine site of the $N$-methyl-D-aspartate receptor. Proc. Natl. Acad. Sci. 97: 4926-4931.

Morita, Y., Ujike, H., Tanaka, Y., Otani, K., Kishimoto, M., Morio, A., Kotaka, T., Okahisa, Y., Matsushita, M., Morikawa, A., et al. 2007. A genetic variant of the serine racemase gene is associated with schizophrenia. Biol. Psychiatry 61: 1200-1203.

Nicoll, R.A. 2003. Expression mechanisms underlying long-term potentiation: A postsynaptic view. Philos. Trans. R. Soc. Lond. B Biol. Sci. 358: $721-726$.

Nicholls, R.E., Alarcon, J.M., Malleret, G., Carroll, R.C., Grody, M., Vronskaya, S., and Kandel, E.R. 2008. Transgenic mice lacking NMDARdependent LTD exhibit deficits in behavioral flexibility. Neuron 58: 104-117.

Norberg, M.M., Krystal, J.H., and Tolin, D.F. 2008. A meta-analysis of Dcycloserine and the facilitation of fear extinction and exposure therapy. Biol. Psychiatry 63: 1118-1126.

Pantelis, C., Barber, F.Z., Barnes, T.R., Nelson, H.E., Owen, A.M., and Robbins, T.W. 1999. Comparison of set-shifting ability in patients with chronic schizophrenia and frontal lobe damage. Schizophr. Res. 37: 251-270.

Pitkänen, M., Sirviö, J., MacDonald, E., Ekonsalo, T., and Riekkinen Sr., P. 1995. The effects of D-cycloserine, a partial agonist at the glycine binding site, on spatial learning and working memory in scopolaminetreated rats. J. Neural Transm. Park. Dis. Dement. Sect. 9: 133-144.

Ressler, K.J., Rothbaum, B.O., Tannenbaum, L., Anderson, P., Graap, K. Zimand, E., Hodges, L., and Davis, M. 2004. Cognitive enhancers as adjuncts to psychotherapy: Use of D-cycloserine in phobic individuals to facilitate extinction of fear. Arch. Gen. Psychiatry 61: 1136-1144.

Sasaki, M., Konno, R., Nishio, M., Niwa, A., Yasumura, Y., and Enami, J. 1992. A single-base-pair substitution abolishes D-amino-acid oxidase activity in the mouse. Biochim. Biophys. Acta 1139: 315-318.

Schell, M.J., Molliver, M.E., and Snyder, S.H. 1995. D-serine, an endogenous synaptic modulator: Localization to astrocytes and glutamatestimulated release. Proc. Natl. Acad. Sci. 92: 3948-3952.

Schell, M.J., Brady Jr., R.O., Molliver, M.E., and Snyder, S.H. 1997. D-serine as a neuromodulator: Regional and developmental localizations in rat brain glia resemble NMDA receptors. J. Neurosci. 17: 1604-1615.

Schumacher, J., Jamra, R.A., Freudenberg, J., Becker, T., Ohlraun, S., Otte, A.C., Tullius, M., Kovalenko, S., Bogaert, A.V., Maier, W., et al. 2004. Examination of G72 and D-amino acid oxidase as genetic risk factor for schizophrenia and bipolar affective disorder. Mol. Psychiatry 9: 203-207.

Shoji, K., Mariotto, S., Ciampa, A.R., and Suzuki, H. 2006. Mutual regulation between serine and nitric oxide metabolism in human glioblastoma cells. Neurosci. Lett. 394: 163-167.

Sotres-Bayon, F., Bush, D.E., and LeDoux, J.E. 2007. Acquisition of fear extinction requires activation of NR2B-containing NMDA receptors in the lateral amygdala. Neuropsychopharmacology 32: 1929-1940.
Szapiro, G., Vianna, M.R., McGaugh, J.L., Medina, J.H., and Izquierdo, I. 2003. The role of NMDA glutamate receptors, PKA, MAPK, and CAMKII in the hippocampus in extinction of conditioned fear. Hippocampus 13: 53-58.

Tang, Y.P., Shimizu, E., Dube, G.R., Rampon, C., Kerchner, G.A., Zhuo, M., Liu, G., and Tsien, J.Z. 1999. Genetic enhancement of learning and memory in mice. Nature 401: 63-69.

Tronson, N.C. and Taylor, J.R. 2007. Molecular mechanisms of memory reconsolidation. Nat. Rev. Neurosci. 8: 262-275.

Tsai, G., Yang, P., Chung, L.-C., Lange, N., and Coyle, J.T. 1998. D-serine added to antipsychotics for the treatment of schizophrenia. Biol. Psychiatry 44: 1081-1089.

Valentinuzzi, V.S., Kolker, D.E., Vitaterna, M.H., Shimomura, K., Whiteley, A., Low-Zeddies, S., Turek, F.W., Ferrari, E.A., Paylor, R., and Takahashi, J.S. 1998. Automated measurement of mouse freezing behavior and its use for quantitative trait locus analysis of contextual fear conditioning in $(\mathrm{BALB} / \mathrm{cJ} \times \mathrm{C} 57 \mathrm{BL} / 6 \mathrm{~J}) \mathrm{F}_{2}$ mice. Learn. Mem. 5: 391-403.

van der Meulen, J.A., Bilbija, L., Joosten, R.N., de Bruin, J.P., and Feenstra, M.G. 2003. The NMDA-receptor antagonist MK-801 selectively disrupts reversal learning in rats. Neuroreport 14: 2225-2228.

Wake, K., Yamazaki, H., Hanzawa, S., Konno, R., Sakio, H., Niwa, A., and Hori, Y. 2001. Exaggerated responses to chronic nociceptive stimuli and enhancement of $N$-methyl-D-aspartate receptor-mediated synaptic transmission in mutant mice lacking D-amino-acid oxidase. Neurosci. Lett. 297: 25-28.

Wass, C., Svensson, L., Fejgin, K., Pålsson, E., Archer, T., Engel, J.A., and Klamer, D. 2008. Nitric oxide synthase inhibition attenuates phencyclidine-induced disruption of cognitive flexibility. Pharmacol. Biochem. Behav. 89: 352-359.

Watanabe, Y., Himi, T., Saito, H., and Abe, K. 1992. Involvement of glycine site associated with the NMDA receptor in hippocampal long-term potentiation and acquisition of spatial memory in rats. Brain Res. 582: 58-64.

Whishaw, I.Q. and Tomie, J.A. 1997. Perseveration on place reversals in spatial swimming pool tasks: Further evidence for place learning in hippocampal rats. Hippocampus 7: 361-370.

Wolosker, H., Sheth, K.N., Takahashi, M., Mothet, J., Brady Jr., R.O., Ferris, C.D., and Snyder, S.H. 1999. Purification of serine racemase: Biosynthesis of the neuromodulator d-serine. Proc. Natl. Acad. Sci. 96: 721-725.

Wong, G.T. 2002. Speed congenics: Applications for transgenic and knockout mouse strains. Neuropeptides 36: 230-236.

Wu, S.Z., Bodles, A.M., Porter, M.M., Griffin, W.S., Basile, A.S., and Barger, S.W. 2004. Induction of serine racemase expression and D-serine release from microglia by amyloid $\beta$-peptide. J. Neuroinflammation 1: 2 . doi: 10.1186/1742-2094-1-2.

Yang, Y., Ge, W., Chen, Y., Zhang, Z., Shen, W., Wu, C., Poo, M., and Duan, S. 2003. Contribution of astrocytes to hippocampal long-term potentiation through release of d-serine. Proc. Natl. Acad. Sci. 100: 15194-15199.

Young, E.J., Lipina, T., Tam, E., Mandel, A., Clapcote, S.J., Bechard, A.R., Chambers, J., Mount, H.T., Fletcher, P.J., Roder, J.C., et al. 2008. Reduced fear and aggression and altered serotonin metabolism in Gtf2ird1targeted mice. Genes Brain Behav. 7: 224-234.

Zeng, H., Chattarji, S., Barbarosie, M., Rondi-Reig, L., Philpot, B.D., Miyakawa, T., Bear, M.F., and Tonegawa, S. 2001. Forebrain-specific calcineurin knockout selectively impairs bidirectional synaptic plasticity and working/episodic-like memory. Cell 107: 617-629.

Zhang, Z., Gong, N., Wang, W., Xu, L., and Xu, T.L. 2008. Bell-shaped D-serine actions on hippocampal long-term depression and spatial memory retrieval. Cereb. Cortex 18: 2391-2401.

Received June 18, 2008; accepted in revised form October 27, 2008. 


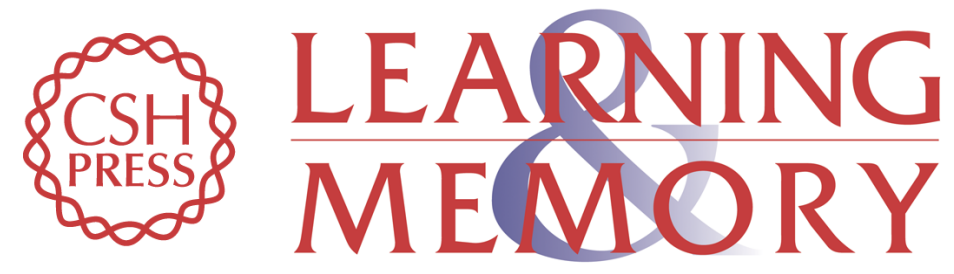

\section{Genetic inactivation of D-amino acid oxidase enhances extinction and reversal learning in mice}

Viviane Labrie, Steven Duffy, Wei Wang, et al.

Learn. Mem. 2009, 16:

Access the most recent version at doi:10.1101//m.1112209

References This article cites 71 articles, 15 of which can be accessed free at:

http://learnmem.cshlp.org/content/16/1/28.full.html\#ref-list-1

License

Email Alerting Receive free email alerts when new articles cite this article - sign up in the box at the Service top right corner of the article or click here. 